\title{
Editorial on the article entitled "Secondary surgical-site infection after coronary artery bypass grafting: A multi-institutional prospective cohort study"
}

\author{
Francesco Nicolini \\ Department of Medicine and Surgery, University of Parma, Parma, Italy \\ Correspondence to: Francesco Nicolini, MD, PhD. Department of Medicine and Surgery, University of Parma, Via A. Gramsci 14, 43126 Parma, Italy. \\ Email: francesco.nicolini@unipr.it. \\ Comment on: Gulack BC, Kirkwood KA, Shi W, et al. Secondary surgical-site infection after coronary artery bypass grafting: A multi-institutional \\ prospective cohort study. J Thorac Cardiovasc Surg 2018;155:1555-62.e1.
}

Submitted Aug 21, 2018. Accepted for publication Sep 04, 2018.

doi: $10.21037 /$ jtd.2018.09.70

View this article at: http://dx.doi.org/10.21037/jtd.2018.09.70

Saphenous vein grafts (SVGs) are commonly used in coronary artery bypass graft (CABG) operations, but this procedure is burdened by leg secondary surgical-site infections (SSIs), lymphoedema, wound dehiscence, and potential skin flap necrosis. It is well recognized that the incidence of leg SSIs depends on the harvesting technique, and presents with a wide range of occurrence (1-4).

Leg SSIs are an important cause of hospital readmission after bypass surgery (5) and increase health care costs, due to the evidence of prolonged length of hospital stay, need of long-time antibiotics therapy, and frequent outpatient and in-hospital medications. However, few studies have been published reporting data on risk factors and consequences of these infections. Moreover, few studies focused on SSI as the primary endpoint, most of them are retrospective single-center analyses, with a significant lack of data during follow-up (4,6-14).

Recently, Gulack et al. (15) reported the results of their multi-institutional prospective cohort study designed with the aim to analyze patient risk factors and care management associated with SSI after CABG. The first peculiarity of this study was that the primary outcome of interest was the incidence of SSI of the secondary incision site in the leg or groin (e.g., saphenous vein harvest site, perfusion cannulation site). The authors selected all patients in the Cardiothoracic Surgical Trials Network (CTSN) study who underwent a CABG procedure (with or without concomitant procedures) with saphenous vein conduit harvesting, and compared patients who did and did not develop a secondary SSI in terms of baseline characteristics, operative characteristics, postoperative management, and outcomes. Study population consisted of 2,174 patients, of whom $65(3.0 \%)$ developed a secondary SSI within 65 days of the index operation, with a median time to secondary SSI of 16 days. Most of these infections were diagnosed after discharge from the index hospitalization $(\mathrm{n}=56,86 \%)$, particularly within 30 days of discharge $(n=46,82 \%)$. The majority of the secondary SSIs were superficial and only 8 (12\%) were defined as deep. Baseline demographics, cardiac and non-cardiac morbidities were similar between groups, with the exception of body mass index (BMI), which resulted significantly more increased in patients who developed SSIs. Operative characteristics including type of procedure, urgency of surgery, operative time, cardiopulmonary bypass time, and number of vein anastomoses resulted not significantly different between groups. Interestingly endoscopic vein harvesting technique was significantly less frequently used in patients with secondary SSI. Another important finding was that patients who developed a secondary SSI significantly received a larger transfusion of packed red blood cells (PRBCs) during their index hospitalization than patients who did not have an SSI. No relationship between preoperative anemia and the risk of infection or the risk associated with transfusion were found. Finally, there were no significant differences in infection rates in terms of type of surgical scrub, type of antibiotic therapy, duration of antimicrobial therapy postoperatively, or presence or absence of postoperative 
hyperglycemia.

The authors found that factors related to the occurrence of SSIs at multivariable analysis (with death as a competing risk) were the use of an open saphenous graft harvesting approach, increased BMI, and PRBC transfusion. It is noteworthy that more patients who developed a secondary SSI were readmitted within 65 days of surgery than control patients $(34 \%$ vs. $17 \%, \mathrm{P}<0.01)$, mostly for secondary SSI, although SSIs incidence was never related to higher mortality rate in this group of patients. The authors clearly confirm that, in this large, prospective, multiinstitutional cohort study, secondary SSIs after CABG with SVG conduits are not an uncommon event, and that are associated with more frequent hospital readmissions.

Important findings of this study were that SSI have been reported more frequently in patients who had open traditional saphenous vein harvesting technique, received more units of PRBCs, and have an increased BMI. I personally agree with the authors that the most interesting finding of this study is that a typical 30 days follow-up after the index operation is unable to detect the majority of secondary SSIs after CABG, and that this was actually possible for the authors only extending patients follow-up to 65 days after the index operation.

Indeed, on this line Hassoun-Kheir et al. (16) performed a retrospective cohort study in a primary and tertiary hospital including all adult patients undergoing CABG with open saphenous vein harvesting with the aim to investigate risk factors for limb surgical site infection following this procedure. Patients were followed perioperatively from admission until 90 days postoperatively, including postdischarge follow-up. Also, in this study leg SSI resulted in significantly prolonged hospital stays after surgery, longer antibiotic therapy and more frequent rates of readmissions. However, the authors found that only female sex, peripheral vascular disease, and obesity were independent risk factors for leg SSIs.

The reported incidence of $3.0 \%$ of SSIs in the study of Gulack et al. (15) at 65 days of follow-up, is similar to other published observational studies, although most of these studies were designed with a primary aim to investigate at long-term clinical consequences of endoscopic versus open saphenous vein harvest in CABG $(3-4,12,16)$. Like other recent published studies, the results of Gulack et al. (15) confirm that endoscopic saphenous vein harvesting is associated with a significantly lower incidence of secondary SSIs in patients after CABG $(3,4,10-12,14,16)$.

This scientific evidence comparing endoscopic versus open saphenous vein harvesting shows that endoscopic approach allows two- and three-fold improvements in the rate of wound related complications and infections, significantly improves patient outcome, shorter hospital stay, and reduced postoperative pain. Concerns about endoscopic vein harvesting are still related to potential risk of injury of the vein at the time of harvest with consequent poor-quality grafts conditioning a potential negative impact on vein graft patency and long-term clinical outcomes.

A recent meta-analysis of randomized controlled trials (RCT) and observational trials (OT) has been recently published by Deppe et al. (17). The authors investigated the impact of endoscopic vein harvesting on adverse clinical outcomes after CABG in terms of wound infection, postoperative pain, myocardial infarction, vein graft failure, length of hospital stays, and mortality.

A total of 27,789 patients from 43 studies (16 RCT and 27 OT) were considered and included. Endoscopic approach was performed in $46 \%$ of patients $(n=12,822)$ and open traditional technique in $54 \%(n=14,967)$. Pooled effect estimates showed a significant reduced incidence for wound infections, pain, and length of hospital stay for endoscopic technique. Interestingly, endoscopic approach resulted associated to an increase of the odds for vein graft failure, that however lost statistical difference after pooled analysis of RCT and studies with high methodological quality. Other graft-related clinical endpoints, as mortality and myocardial infarction, did not show differences between both techniques. The authors concluded that this systematic review underlines the safety of endoscopic saphenous vein approach in patients undergoing CABG.

The 2014 European Society of Cardiology/European Association for Cardio-Thoracic Surgery guidelines on myocardial revascularization recommend endoscopic vein harvesting with the aim to reduce the incidence of leg SSIs (level of evidence A, class of recommendation moderate, IIa), although they stress that this procedure should be performed by experienced surgeons (18).

This recommendation is based on the evidence that poor conduit quality, as a consequence of the learning curve for endoscopic approach, has been shown to be a predictor of early graft failure, potentially affecting also clinical outcomes of the patients. Consequently, there is still matter of debate on the choice of strategies finalized at reducing the negative impact of learning curve on vein graft quality.

Endoscopic saphenous vein harvesting procedure should be initiated only by some dedicated surgeons in each center 
and extended to the other components of the team only at the end of their learning curve. In my center, we deserve endoscopic approach to diabetic patients and to young candidates to CABG. We are trying to perform a systematic preoperative screening with echo-doppler examination of the saphenous system in order to decide the eventual endoscopic harvesting. The criteria that we currently adopt are the presence of a regular and not tortuous course, the preference of an under fascial course of saphenous conduit, and its dimensions between 3.5 and $5 \mathrm{~mm}$ (calculated with the patient in an upright position), while obviously the absolute criterion of exclusion is the presence of varices. This approach allows us to select the most suitable conducts for endoscopic harvesting, to reduce unnecessary or ineffective endoscopic procedures, and to limit the problems related to the learning curve.

Other methods other than endoscopic harvesting have been adopted or are under evaluation in order to reduce leg SSIs after saphenous vein grafting but their results are not definitely conclusive. Bridged incisions instead of a single linear incision, the use of postoperative antimicrobial skin sealant attachments, and biostatic triclosan-coated sutures were proved ineffective or are still a matter of debate (19-21). Biancari et al. compared the rates of SSIs and wound dehiscence after staples versus traditional sutures for skin closure after SVG harvesting for CABG, but they found no evidence of a difference in the risk of SSI between both approaches (22). Lommerud et al. (23) evaluated the use of a graduated compression stocking for 4-6 weeks after CABG on the leg with the saphenous vein harvest site but again no evidence was found in terms of reduction of the incidence of harvest site surgical wound infection.

Until more and exhaustive data will be provided from future adequately powered trials, studies like that published by Gulack et al. (15) confirm that endoscopic vein harvesting is a safe alternative to open traditional approach for patients undergoing CABG with venous grafts, according to the consensus statement of the International Society for Minimally Invasive Cardiothoracic Surgery (10).

\section{Acknowledgements}

None.

\section{Footnote}

Conflicts of Interest: The author has no conflicts of interest to declare.

\section{References}

1. Sharma M, Fakih MG, Berriel-Cass D, et al. Harvest surgical site infection following coronary artery bypass grafting: risk factors, microbiology, and outcomes. Am J Infect Control 2009;37:653-7.

2. Olsen MA, Sundt TM, Lawton JS, et al. Risk factors for leg harvest surgical site infections after coronary artery bypass graft surgery. J Thorac Cardiovasc Surg 2003;126:992-9.

3. Williams JB, Peterson ED, Brennan JM, et al. Association between endoscopic vs open vein-graft harvesting and mortality, wound complications, and cardiovascular events in patients undergoing CABG surgery. JAMA 2012;308:475-84.

4. Dacey LJ, Braxton JH, Kramer RS, et al. Long-term outcomes of endoscopic vein harvesting after coronary artery bypass grafting. Circulation 2011;123:147-53.

5. Hannan EL, Zhong Y, Lahey SJ, et al. 30-Day readmissions after coronary artery bypass graft surgery in New York State. JACC Cardiovasc Interv 2011;4:569-76.

6. Shahian DM, O'Brien SM, Filardo G, et al. The Society of Thoracic Surgeons 2008 Cardiac Surgery Risk Models: Part 1-Coronary Artery Bypass Grafting Surgery. Ann Thorac Surg 2009;88:S2-22.

7. Lopes RD, Hafley GE, Allen KB, et al. Endoscopic versus open vein-graft harvesting in coronary-artery bypass surgery. N Engl J Med 2009;361:235-44.

8. Yun KL, Wu Y, Aharonian V, et al. Randomized trial of endoscopic versus open vein harvest for coronary artery bypass grafting: six-month patency rates. J Thorac Cardiovasc Surg 2005;129:496-503.

9. Andreasen JJ, Nekrasas V, Dethlefsen C. Endoscopic vs open saphenous vein harvest for coronary artery bypass grafting: a prospective randomized trial. Eur J Cardiothorac Surg 2008;34:384-9.

10. Allen K, Cheng D, Cohn W, et al. Endoscopic vascular harvest in coronary artery bypass grafting surgery: a consensus statement of the International Society of Minimally Invasive Cardiothoracic Surgery (ISMICS) 2005. Innovations (Phila) 2005;1:51-60.

11. Markar SR, Kutty R, Edmonds L, et al. A meta-analysis of minimally invasive versus traditional open vein harvest technique for coronary artery bypass graft surgery. Interact Cardiovasc Thorac Surg 2010;10:266-70.

12. Ouzounian M, Hassan A, Buth KJ, et al. Impact of endoscopic versus open saphenous vein harvest techniques on outcomes after coronary artery bypass grafting. Ann 
Thorac Surg 2010;89:403-8.

13. Shroyer AL, Grover FL, Hattler B, et al. On-pump versus off-pump coronary-artery bypass surgery. N Engl J Med 2009;361:1827-37.

14. Zenati MA, Shroyer AL, Collins JF, et al. Impact of endoscopic versus open saphenous vein harvest technique on late coronary artery bypass grafting patient outcomes in the ROOBY (Randomized On/Off Bypass) trial. J Thorac Cardiovasc Surg 2011;141:338-44.

15. Gulack BC, Kirkwood KA, Shi W, et al; Cardiothoracic Surgical Trials Network (CTSN). Secondary surgical-site infection after coronary artery bypass grafting: A multiinstitutional prospective cohort study. J Thorac Cardiovasc Surg 2018;155:1555-62.e1.

16. Hassoun-Kheir N, Hasid I, Bozhko M, et al. Risk factors for limb surgical site infection following coronary artery bypass graft using open great saphenous vein harvesting: a retrospective cohort study. Interact Cardiovasc Thorac Surg 2018. [Epub ahead of print].

17. Deppe AC, Liakopoulos OJ, Choi YH, et al. Endoscopic vein harvesting for coronary artery bypass grafting: a systematic review with meta-analysis of 27,789 patients. J Surg Res 2013;180:114-24.

18. Windecker S, Kolh P, Alfonso F, et al. 2014 ESC/EACTS Guidelines on myocardial revascularization: the Task Force on Myocardial Revascularization of the European Society of Cardiology (ESC) and the European Association for
Cardio-Thoracic Surgery (EACTS). Developed with the special contribution of the European Association of Percutaneous Cardiovascular Interventions (EAPCI). Eur Heart J 2014;35:2541-619.

19. Belczak CE, Tyszka AL, Godoy JM, et al. Clinical complications of limb undergone harvesting of great saphenous vein for coronary artery bypass grafting using bridge technique. Rev Bras Cir Cardiovasc 2009;24:68-72.

20. Falk-Brynhildsen K, Söderquist B, Friberg O, et al. Bacterial growth and wound infection following saphenous vein harvesting in cardiac surgery: a randomized controlled trial of the impact of microbial skin sealant. Eur J Clin Microbiol Infect Dis 2014;33:1981-7.

21. Thimour-Bergström L, Roman-Emanuel C, Scherstén $\mathrm{H}$, et al. Triclosan-coated sutures reduce surgical site infection after open vein harvesting in coronary artery bypass grafting patients: a randomized controlled trial. Eur J Cardiothorac Surg 2013;44:931-8.

22. Biancari F, Tiozzo V. Staples versus sutures for closing leg wounds after vein graft harvesting for coronary artery bypass surgery. Cochrane Database Syst Rev 2010;CD008057.

23. Lommerud S, Hofoss D. Leg wound infection after coronary artery bypass grafting: A natural experiment comparing use and non-use of a compression stocking. Eur J Cardiovasc Nurs 2017;16:136-42.
Cite this article as: Nicolini F. Editorial on the article entitled "Secondary surgical-site infection after coronary artery bypass grafting: A multi-institutional prospective cohort study". J Thorac Dis 2018;10(Suppl 33):S3938-S3941. doi: 10.21037/ jtd.2018.09.70 